Urteil des Bundesgerichtshofs

\title{
Ärzte-Bewertungen strenger prüfen
}

\section{Hier steht eine Anzeige.}

Im Internet Ärzte beschimpfen und über ihre Arbeit meckern: Solche Kommentare könnten künftig schneller aus dem Netz fliegen. Denn der Bundesgerichtshof nimmt die Portale in die Pflicht und verlangt im Zweifel Beweise.
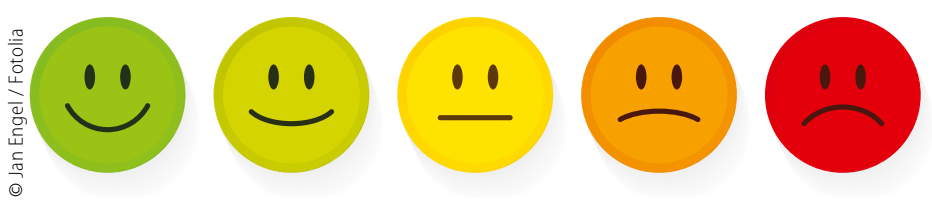

Bewertungsportale müssen die Einschätzungen ihrer Nutzer künftig gründlicher überprüfen und konkrete Nachweise zum Wahrheitsgehalt liefern können. Der Bundesgerichtshof (BGH) in Karlsruhe entschied, dass solche Portale auf Verlangen beispielsweise stichhaltige Belege darüber herausrücken müssen, ob ein Nutzer tatsächlich in der Praxis eines dort bewerteten Arztes oder Anwalts war [Az.: VI ZR 34/15]. Das Urteil hat weitreichende Folgen, auch für andere Portale, die ihre Prüfprozesse nun anpassen müssen.

Im konkreten Fall bekam ein Zahnarzt aus Berlin Recht, der beim Internetportal Jameda im Jahr 2013 eine extrem schlechte Bewertung erhalten und vergeblich auf Löschung geklagt hatte. Der angebliche Patient hatte dreimal die Note sechs vergeben und dem Mediziner damit eine Durchschnittsnote von 4,8 verpasst. Das wollte der Arzt nicht hinnehmen und verlangte Beweise dafür, dass der Patient tatsächlich bei ihm behandelt worden war. Dieser Prüf- und Nachweispflicht sei Jameda nicht ausreichend nachgekommen, so die BGH-Richter.

\section{"Erfreuliches Urteil für die Stärkung des \\ Persönlichkeitsrechts"}

Jameda will seine Prüfprozesse nun entsprechend „ausgestalten“, hieß es in einer Stellungnahme. Im Interesse der Meinungs- und Medienfreiheit seien zwar Meldungen aller Art grundsätzlich zu dulden, aber: „Beanstandungen müssen sorgfältig und gewissenhaft geprüft werden“, so der Vorsitzende Richter Gregor Galke.

Im vorliegenden Fall hätte Jameda den Verfasser der umstrittenen Bewertung auffordern müssen, etwa Bonushefte oder Rezepte vorzulegen. Das habe Jameda aber versäumt. Voigtland bezeichnete die BGH-Entscheidung als „erfreuliches Urteil für die Stärkung des Persönlichkeitsrechts“. Künftig werde es für Betroffene leichter, sich gegen ungerechte Bewertungen zu wehren, fügte Volker Herrmann, Fachanwalt für Urheber- und Medienrecht, hinzu.

„Wir schweben nicht mehr im luftleeren Raum.“ Der BGH erkenne die Missbrauchsmöglichkeiten eines Bewertungsportals an „und versucht mit der Konkretisierung der Prüfpflichten des Portalbetreibers ein Gegengewicht zu schaffen", ergänzte Martin Gerecke, Fachanwalt für Medienrecht. Der zuständige VI. Senat des BGH stellte gleichzeitig aber klar, dass solche Nachweise weiterhin anonymisiert werden dürfen. Laut Telemediengesetz dürfen personenbezogene Daten wie etwa der sogenannte Klarname eines anonymen Bewerters nur dann preisgegeben werden, wenn dieser einverstanden ist, wenn der Staatsanwalt ermittelt oder wenn etwa Urheberrechte verletzt werden. 